\title{
The $13042 \mathrm{G} \rightarrow \mathrm{A} / \mathrm{ND} 5$ mutation in mtDNA is pathogenic and can be associated also with a prevalent ocular phenotype
}

\author{
M L Valentino, P Barboni, C Rengo, A Achilli, A Torroni, R Lodi, C Tonon, B Barbiroli, F Fortuna, \\ P Montagna, A Baruzzi, V Carelli
}

J Med Genet 2006;43:e38 (http://www.jmedgenet.com/cgi/content/full/43/7/e38). doi: 10.1136/jmg.2005.037507

Background: Overlapping phenotypes including LHON, MELAS, and Leigh syndrome have recently been associated with numerous mtDNA point mutations in the ND5 gene of complex I, now considered a mutational hot spot.

Objective: To identify the mtDNA defect in a family with a prevalent ocular phenotype, including LHON-like optic neuropathy, retinopathy, and cataract, but characterised also by strokes, early deaths, and miscarriages on the maternal line.

Results: Sequencing of the entire mitochondrial genome from the proband's muscle DNA identified the heteroplasmic $13042 \mathrm{G} \rightarrow \mathrm{A}$ transition, which was previously described only once in a patient with a different mitochondrial disease. This mutation fulfils the major pathogenic criteria, inducing an amino acid change (A236T) at an invariant position in a highly conserved domain of the ND5 gene. Phosphorus magnetic resonance spectroscopy in the proband disclosed an in vivo brain and skeletal muscle energy metabolism deficit.

Conclusions: These findings conclusively establish the pathogenic role of the $13042 \mathrm{G} \rightarrow \mathrm{A}$ mutation and underscore its variable clinical expression.

l $\mathrm{n}$ recent years an increasing number of point mutations of mitochondrial DNA (mtDNA) in the structural gene encoding the ND5 subunit of complex I have been described associated with mitochondrial encephalomyopathy, lactic acidosis, stroke-like syndrome (MELAS), ${ }^{1-5}$ overlapping Leber's hereditary optic neuropathy (LHON)/ MELAS, $^{245}$ Leigh syndrome, ${ }^{6-10}$ and overlapping Leigh/ MELAS. ${ }^{511}$ Thus the ND5 gene qualifies as an important mutational hot spot for phenotypes bridging LHON/MELAS/ Leigh syndrome. Moreover, recent reports provided evidence that, in a similar fashion, mutations in the ND6 ${ }^{12}$ and NDI ${ }^{13} 14$ subunit genes of complex I may also be associated with LHON/MELAS/Leigh syndrome. Frequently, these patients lacked ragged red fibres in muscle biopsies and invariably had an isolated complex I defect on biochemical investigation.

We present an Italian family with four individuals who suffered from optic atrophy with LHON-like features, the two still alive also having retinopathy and cataract. However, the occurrence of retinopathy, strokes, early deaths, and miscarriages along the maternal line were also reported. In this family we identified the heteroplasmic mtDNA point mutation $13042 \mathrm{G} \rightarrow \mathrm{A}$ in the ND5 gene, which was previously found in a single patient with MERRF/MELAS overlapping syndrome. ${ }^{15}$

\section{CASE REPORTS}

The pedigree is shown in fig 1 .

The proband (IV-4), a 60 year old woman, had suffered common migraine since adolescence. At 39 years of age, she presented with central vision loss sequentially in both eyes, with a one month interval, in association with migraine episodes. Her visual acuity fell to 0.02 in the right eye and 0.4 in the left. Corticosteroids failed to modify her visual defect. She subsequently underwent surgery for "optochiasmatic arachnoiditis" and shortly after her vision was reduced to light perception. The histological report on the arachnoid specimen showed inflammatory features. During the ensuing four years she reported a gradual improvement of her visual function.

We first observed this patient at 49 years of age, after a subjective complaint of a new worsening of her vision. Ophthalmological examination showed complete optic atrophy, retinopathy characterised by yellowish dots deposited in the peripheral and central retina (fig 2A), and a nuclear cataract. The visual field was characterised by a cecocentral scotoma greater than $20^{\circ}$ in size with central fenestration, and her visual acuity was 0.1 in the right eye and 0.4 in the left. She had brisk reflexes on neurological examination, and a consistently increased serum lactic acid after standardised exercise on a cycloergometer was reported on three different occasions $(34.2,43.4$, and $51.80 \mathrm{mg} / \mathrm{dl}$; normal range 9 to 18$)$. At 52 years of age she had a transient episode of prolonged migraine attack with paraesthesiae on the left side of her face including the tongue, objective vertigo, and disequilibrium. She was also complaining of easy fatigability and muscle weakness. A muscle biopsy showed only some subsarcolemmal mitochondrial proliferation as seen by the increase of both succinate dehydrogenase and cytochrome c oxidase staining. All electrophysiological investigations were normal, as well as brain computed tomography and magnetic resonance imaging (MRI), with the exception of the surgery related lesion. The common LHON pathogenic mutations (11778/ND4, 3460/ND1, 14484/ND6) were not found. Treatment with idebenone was started $(270 \mathrm{mg} /$ day increasing to $320 \mathrm{mg} /$ day) and discontinued after a year, having had no appreciable effects on her muscle weakness or visual function. However, after cataract surgery at 53 years of age her visual acuity improved to 0.16 in the right eye and 0.5 in the left. At the time of writing she complained of worsening of exercise intolerance.

Individual $I V-7$, the 56 year old proband's brother, suffered from subacute loss of central vision in the left eye when he

Abbreviations: FID, free induction decay; LHON, Leber's hereditary optic neuropathy; MELAS, mitochondrial encephalomyopathy, lactic acidosis, stroke-like syndrome; MERRF, myoclonic epilepsy, ragged red fibres; m+DNA, mitochondrial DNA; $\mathrm{PCr}$, phosphocreatine 


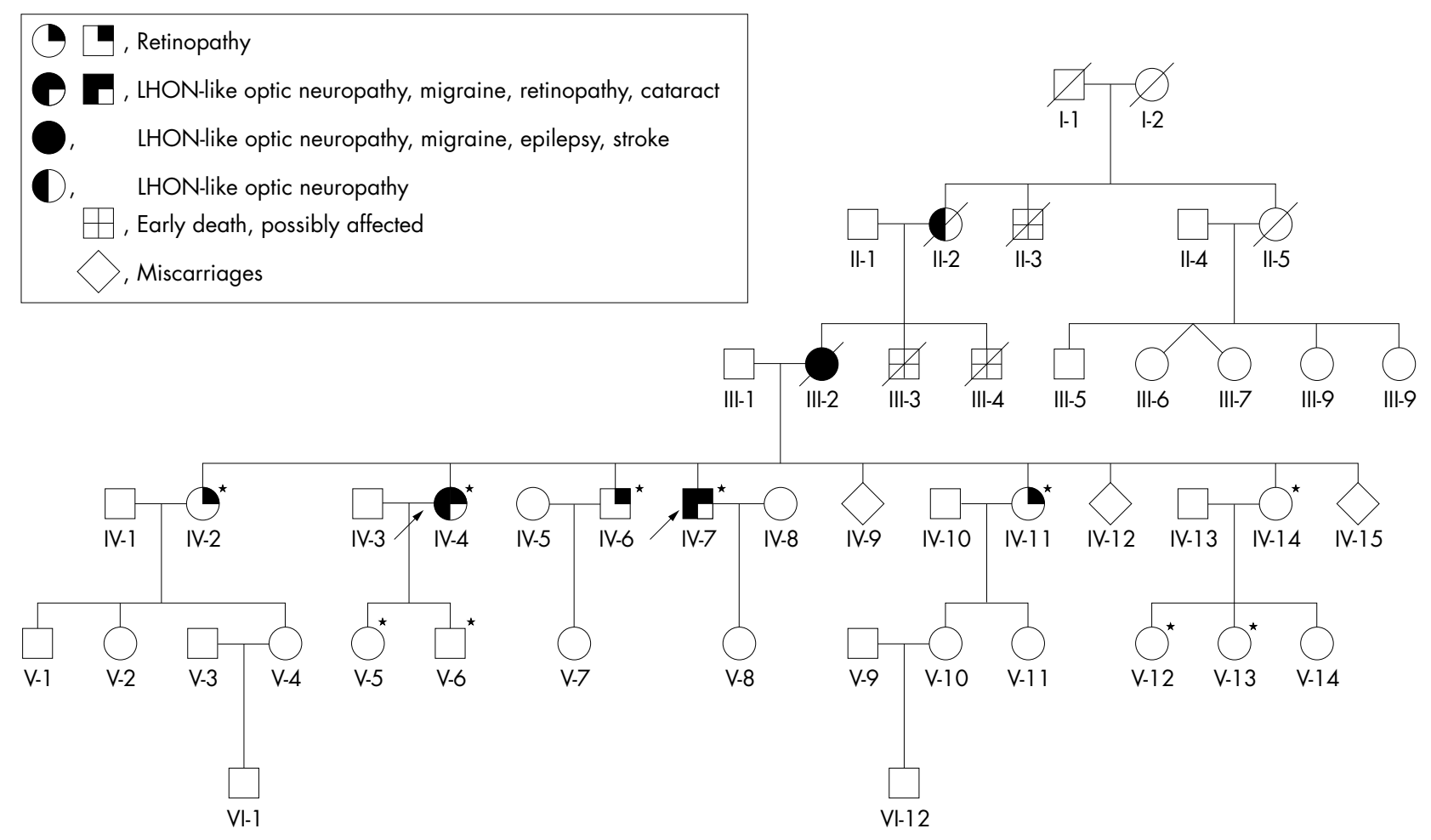

Figure 1 Genealogical tree. Six generations of the pedigree have been reconstructed. Arrows indicate the proband and her brother, the two affected living members. Asterisks indicate the individuals who underwent mtDNA investigation.

was 35, and four months later in the right eye. Fundoscopy showed a pale optic disc in the left eye and a hyperaemic optic nerve head in the right eye. He underwent surgery for "optochiasmatic arachnoiditis". Histological examination of the arachnoid specimen showed an inflammatory picture with hyperplastic fibrosis. One year later the patient experienced gradual improvement in his vision.

When we saw the patient at 45 years of age his visual acuity was 1.0 in both eyes with a cecocentral scotoma between $10^{\circ}$ and $20^{\circ}$ in size. Fundoscopy showed complete optic atrophy and maculopathy (fig 2B). At 52 years of age the patient was re-examined for worsening of visual function. A nuclear cataract was detected and after cataract surgery his visual acuity was 0.8 in the right eye and 0.63 in the left, possibly because of progression of the maculopathy.

Fundus examination in individuals $I V-2, I V-6$, and $I V-11$, showed a mild maculopathy characterised by a variable number of small yellowish dots in the presence of a normal optic disc, with no signs of microangiopathy or nerve fibre layer swelling (fig 2C, table 1).
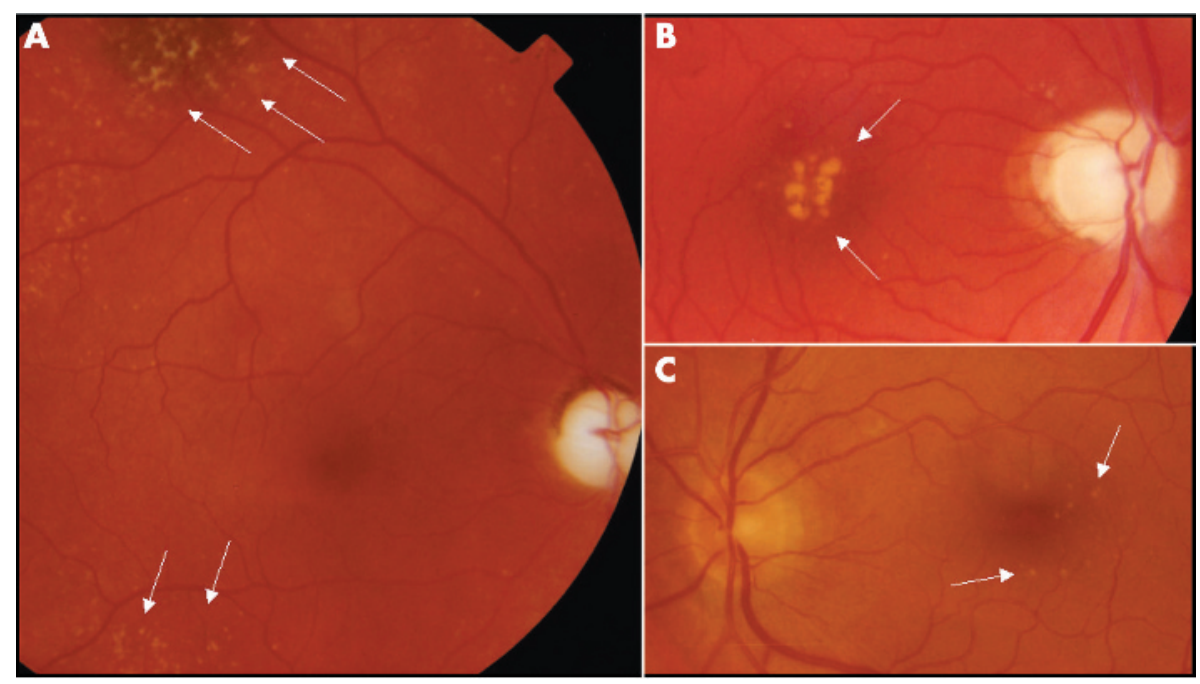

Figure 2 Fundoscopy findings. (A) Right fundus of the proband (IV-4) showing complete optic atrophy and retinopathy characterised by yellowish dots at the level of the retinal pigmented epithelium, with a mainly peripheral distribution, but also present in the macular region. (B) Right fundus of the proband's brother (IV-7) showing complete optic atrophy and retinopathy with confluent yellowish dots localised at the fovea and smaller spare dots in the macular region. (C) Left fundus of the unaffected individual (IV-6) showing a normal papilla with no microangiopathy or nerve fibre swelling, but with evidence of mild retinopathy characterised by discrete, small yellowish dots in the macula. 
Table 1 Ophthalmological findings and heteroplasmy of the 13042G $\rightarrow$ A/ND5 mutation

\begin{tabular}{|c|c|c|c|c|c|c|c|c|c|c|}
\hline Subject & Eye & Age $(y)$ & $\begin{array}{l}\text { Optic } \\
\text { neuropathy }\end{array}$ & $\begin{array}{l}\text { Age of onset of } \\
\text { optic neuropathy } \\
\text { (y) }\end{array}$ & $\begin{array}{l}\text { Final } \\
\text { visual } \\
\text { acuity }\end{array}$ & $\begin{array}{l}\text { Visual field } \\
\text { (size of central } \\
\text { scotoma) }\end{array}$ & $\begin{array}{l}\text { Cataract } \\
\text { (age of } \\
\text { onset) }\end{array}$ & Maculopathy & $\begin{array}{l}\text { Surgery for } \\
\text { "optochiasmatic } \\
\text { arachnoiditis" }\end{array}$ & $\begin{array}{l}\text { Heteroplasmy } \\
\% \text { mutant mtDNA }\end{array}$ \\
\hline IV-4 & $\begin{array}{l}\mathrm{R} \\
\mathrm{L}\end{array}$ & 60 & $\begin{array}{l}\text { Yes } \\
\text { Yes }\end{array}$ & 39 & $\begin{array}{l}0.16 \\
0.5\end{array}$ & $\begin{array}{l}>20^{\circ} \\
>20^{\circ}\end{array}$ & 49 & $\begin{array}{l}\text { Yes } \\
\text { Yes }\end{array}$ & Yes (age 39) & $\begin{array}{l}39 \text { (urine) } \\
91 \text { (muscle) }\end{array}$ \\
\hline IV-7 & $\begin{array}{l}R \\
L\end{array}$ & 56 & $\begin{array}{l}\text { Yes } \\
\text { Yes }\end{array}$ & 35 & $\begin{array}{l}0.8 \\
0.63\end{array}$ & $\begin{array}{l}10-20^{\circ} \\
10-20^{\circ}\end{array}$ & 52 & $\begin{array}{l}\text { Yes } \\
\text { Yes }\end{array}$ & Yes (age 35) & 41 (urine) \\
\hline IV-2 & $\begin{array}{l}\mathrm{R} \\
\mathrm{L}\end{array}$ & 64 & & - & $\begin{array}{l}1.0 \\
1.0\end{array}$ & & - & $\begin{array}{l}\text { Yes } \\
\text { Yes }\end{array}$ & - & 4 (urine) \\
\hline IV-6 & $\begin{array}{l}\mathrm{R} \\
\mathrm{L}\end{array}$ & 59 & & - & $\begin{array}{l}1.0 \\
1.0\end{array}$ & & - & $\begin{array}{l}\text { Yes } \\
\text { Yes }\end{array}$ & - & 43 (urine) \\
\hline IV-11 & $\begin{array}{l}R \\
L\end{array}$ & 54 & & - & $\begin{array}{l}1.0 \\
1.0\end{array}$ & & - & $\begin{array}{l}\text { Yes } \\
\text { Yes }\end{array}$ & - & 20 (urine) \\
\hline
\end{tabular}

$L$, left; mtDNA, mitochondrial DNA; $R$, right; $y$, years.

Individual III-2, the proband's mother, suffered sudden loss of visual acuity at 18 years of age, partially recovering in the ensuing years. At age 33 she started suffering from myoclonic jerks in the right arm, which on some occasions were associated with critical episodes characterised by speech arrest and myoclonic jerks at the corner of the mouth lasting a few minutes. These episodes became progressively more frequent and she died at 41 years of age after a stroke.

Individual II-2, the maternal grandmother, was reported as having suffered poor vision from an early age.

Three individuals along the maternal line died at a young age. Individuals III-3 and III-4 were said to have died of "meningitis" at 15 and 11 years of age, respectively, while individual II-3 died aged two years from "bronchopneumonia". Finally, the proband's mother (III-2) had three miscarriages besides the successful birth of six children.

\section{METHODS}

Total DNA was extracted by standard phenol-chloroform method from leucocyte/platelet pellets and urinary epithelium of 10 maternally related family members, after informed consent had been obtained from the patients and approval for the study from the University board. DNA from the proband's skeletal muscle was also obtained and was used to carry out sequencing of the entire mtDNA, as previously described. ${ }^{16}$ Heteroplasmy of the $13042 \mathrm{G} \rightarrow \mathrm{A} / \mathrm{ND} 5$ mtDNA point mutation was investigated by polymerase chain reaction (PCR) amplification of a convenient mtDNA fragment using the following primers: forward, 13011-13041 (C/ $\mathrm{T}$ mismatch at position 13040 introducing the MseI-TTAA restriction site in the mutant mtDNA); reverse, 13227-13208. Mutant loads were evaluated by hot last cycle $\mathrm{PCR}^{17}$ and by separating the MseI generated restriction fragments on a $12 \%$ acrylamide gel.

\section{Phosphorus magnetic resonance spectroscopy}

${ }^{31} \mathrm{P}-\mathrm{MRS}$ was undertaken using a GE 1.5 T Signa system with a spectroscopy accessory employing a $7.5 \mathrm{~cm}$ diameter surface coil provided by GE, and according to the quantification and quality assessment protocols defined by the EEC concerted research project on "Tissue characterisation by MRS and MRI", COMAC-BME II.1.3. ${ }^{18}$

Brain phosphorus magnetic resonance spectroscopy $\left({ }^{31} \mathrm{P}\right.$ MRS) was undertaken on the occipital lobes by positioning a surface coil on the occipital region after imaging the brain. ${ }^{19}$ The DRESS (depth resolved, surface coil spectroscopy) localisation technique ${ }^{20}$ was used to avoid contribution to the signal by neck muscles, skin, and other interposed tissues. On the basis of proton sagittal images of the brain, a $2.5 \mathrm{~cm}$ thick coronal slice, including both sides, was selected. ${ }^{19}$ The resulting volume of interest can be estimated to be about $90 \mathrm{~cm}^{3}$. The repetition time was five seconds. The flip angle in the selected volume was approximately $30^{\circ}$, and

\section{LHON/MELAS (A236T) ${ }^{\star}$ LHON/MELAS/Leigh (M237L) ${ }^{\dagger}$}

Homo sapiens

Rattus norvegicus

Bos Taurus

Rhinoceros unicornis

Mus musculus

Gallus gallus

Neurospora crassa

Caernorhabditis elegans

Drosphila melanogaster
Xenopus laevis

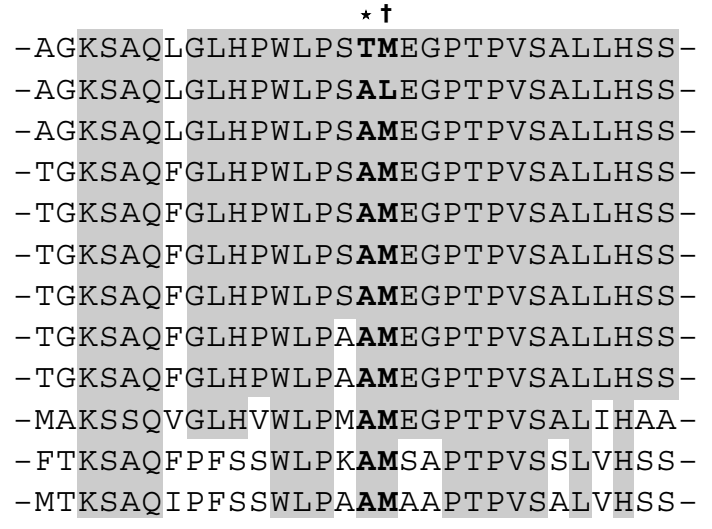

Figure 3 Conservation analysis. ND5 sequence alignment shows that the A236 amino acid residue, mutated to T236 in our family, is invariant. This amino acid position is adjacent to another invariant position (M237), previously found to be mutated because of the 13045A $\rightarrow$ C/ND5 transition (M237L) in a patient with overlapping LHON/MELAS/Leigh syndrome. ${ }^{5}$ Both invariant positions A236 and M237 are located within a very highly conserved domain of the ND5 subunit and are presumably important for complex I function. LHON, Leber's hereditary optic neuropathy; MELAS, mitochondrial encephalomyopathy, lactic acidosis, stroke-like syndrome. 


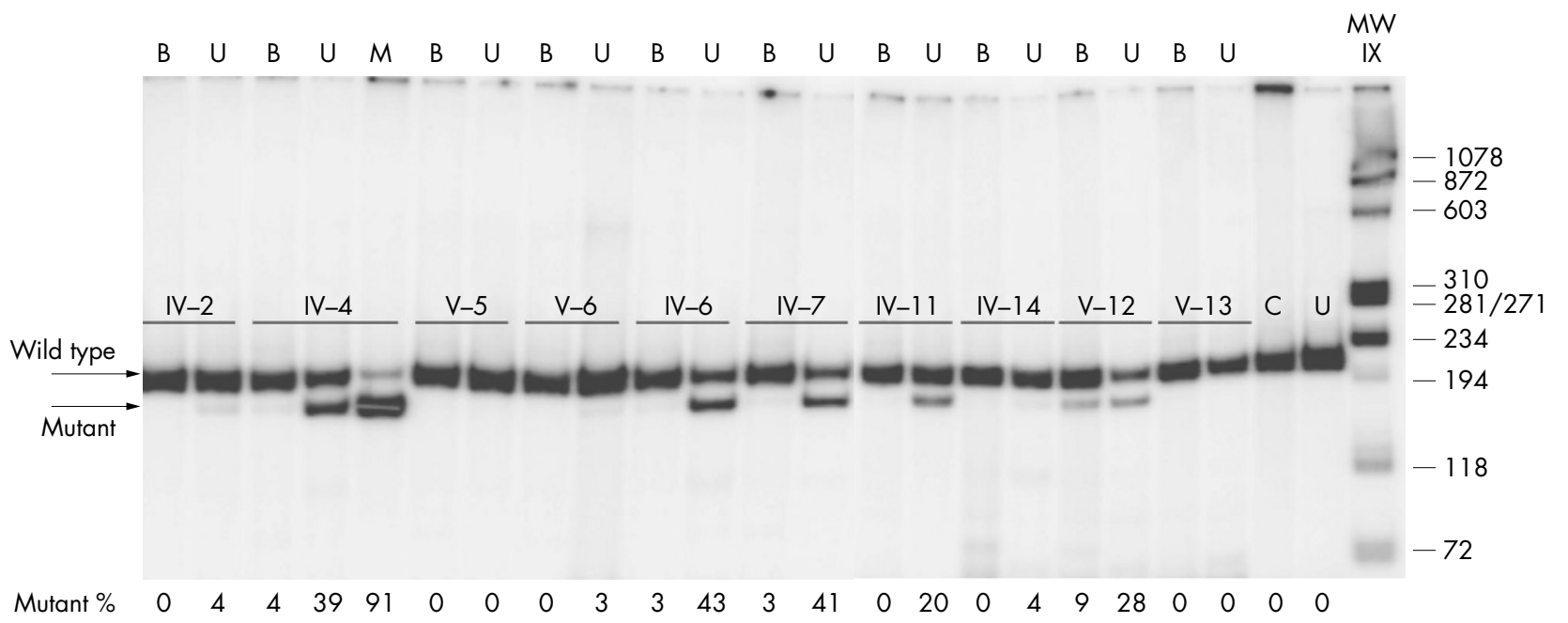

Figure 4 Restriction analysis. Polyacrylamide gel with the Msel restriction analysis of the 13042G $\rightarrow$ A mutation. B, blood; $U$, urinary epithelium; $M$, skeletal muscle; $C$, control; $U$, uncut. The 216 base pair (bp) amplicon is cut into two fragments of 187 and 29 bp (not shown) in the presence of the $13042 \mathrm{G} \rightarrow \mathrm{A}$ mutation. In four cases the mutation was not detected in the blood but was present in the urinary epithelium (IV-2, V-6, IV-1 1, and IV-14). In the other four individuals the mutational load in the urinary epithelium was always strikingly higher than in blood (IV-4, IV-6, IV-7, and V-12). The two affected individuals (IV-4 and IV-7) had high mutant loads in the urinary epithelium and the proband showed over $90 \%$ mutant mtDNA in her skeletal muscle.

it was not necessary to introduce any correction for saturation effects resulting from the repetition time. Four hundred free induction decays (FIDs) were accumulated to obtain a signal to noise ratio of 9 to 12 for $\beta$-ATP. A computed curve fitting program was used to quantify the individual peaks of the spectrum. By assuming a cytosolic [ATP] of $3 \mathrm{mM}^{20}$ we calculated the concentration of phosphocreatine $(\mathrm{PCr})$ and inorganic phosphate (Pi). In order to determine the phosphorylation potential $(\mathrm{PP}=[\mathrm{ATP}] /([\mathrm{ADP}] \times[\mathrm{Pi}])-\mathrm{a}$ global index of readily available free energy in the cell-free cytosolic ADP concentration was calculated from the creatine kinase reaction. ${ }^{19}$

Muscle ${ }^{31} \mathrm{P}$-MRS was undertaken on the right calf muscle by the pulse and acquire technique (repetition time five seconds) at rest, during in-magnet aerobic incremental exercise of plantar flexion, and during recovery from exercise. Sixty FIDs were accumulated during rest (five minutes); then exercise was begun and data collected for one minute (12 FIDs) for each level of work. As soon as the last minute of work was completed and the corresponding 12 FIDs recorded, one 2-FID data block ( 10 seconds) was also recorded, to be considered zero time, and the exercise stopped immediately afterwards. During postexercise recovery, 10 second data blocks (2 FIDs) were recorded during the first 60 seconds, and 30 second data blocks thereafter for another four minutes. The limits of all the peaks were marked manually on each spectrum after phasing, and areas calculated between the limits. ${ }^{19}$ The rate of muscle mitochondrial ATP production was assessed by measuring the rate of $\mathrm{PCr}$ resynthesis during recovery that is entirely oxidative. The rate of $\mathrm{PCr}$ resynthesis was calculated from the monoexponential equation best fitting the experimental points of recovery, and reported as time constants. In view of the influence of the minimum cytosolic $\mathrm{pH}$ reached during recovery on $\mathrm{PCr}$ recovery rate, all time constants were normalised to a cytosolic $\mathrm{pH}=7.00 .{ }^{19}$ Intracellular $\mathrm{pH}$ was calculated from the chemical shift of Pi relative to PCr.

Control subjects were 10 age matched females (mean (SD) age, 60 (3) years). Individual results were taken as abnormal when they fell outside \pm 2 SD of the mean value obtained in healthy controls.

\section{RESULTS}

Based on the maternal recurrence of an LHON-like phenotype and a skeletal muscle mitochondrial dysfunction, as evidenced by the consistent increase of serum lactic acid and mitochondrial proliferation at muscle biopsy of the proband, we sequenced the entire mtDNA. It turned out to be a member of haplogroup $\mathrm{H}$, the most common lineage in Europe $(40-50 \%)$, and in particular of the recently reported subhaplogroup H13. ${ }^{21}$ Relative to the root of the haplogroup, the proband's mtDNA harboured only one non-synonymous

Table $2{ }^{31}$ P-MRS data from occipital lobes and calf muscle of the proband (case IV-4) harbouring the $13042 \mathrm{G} \rightarrow \mathrm{A} / \mathrm{ND} 5$ m+DNA mutation

\begin{tabular}{|c|c|c|c|c|c|c|c|}
\hline & \multicolumn{4}{|l|}{ Occipital lobes } & \multicolumn{3}{|l|}{ Calf muscle } \\
\hline & {$[\mathrm{PCr}](\mathrm{mM})$} & {$[\mathrm{Pi}](\mathrm{mM})$} & [ADP] $(\mu \mathrm{M})$ & $\mathrm{PP}\left(\mathrm{mM}^{-1}\right)$ & $\mathrm{PCr}(\mathrm{mM})$ rest & Pi (mM) rest & $\begin{array}{l}\text { Post-exercise } \\
\mathrm{TC} \mathrm{PCr}(\mathrm{s})\end{array}$ \\
\hline Case (IV-4) & $3.79 *$ & $1.69^{*}$ & $37^{*}$ & $49^{*}$ & 27.2 & 4.16 & $55^{*}$ \\
\hline $\begin{array}{l}\text { Control } \\
\text { (mean (SD)) } \\
\text { (range) }\end{array}$ & $\begin{array}{l}4.57(0.19) \\
(4.16 \text { to } 4.78)\end{array}$ & $\begin{array}{l}1.36(0.13) \\
(1.11 \text { to } 1.50)\end{array}$ & $\begin{array}{l}27 \text { (2) } \\
(24 \text { to } 32)\end{array}$ & $\begin{array}{l}81(5) \\
(74 \text { to } 90)\end{array}$ & $\begin{array}{l}27.9(1.12) \\
(25.5 \text { to } 29.2)\end{array}$ & $\begin{array}{l}4.02(0.56) \\
(3.12 \text { to } 4.80)\end{array}$ & $\begin{array}{l}19(4) \\
(11 \text { to } 27)\end{array}$ \\
\hline
\end{tabular}

*Outside the normal range.

MRS, magnetic resonance spectroscopy; $\mathrm{PCr}$, phosphocreatine; $\mathrm{Pi}$, inorganic phosphate; PP, phosphorylation potential $(=[\mathrm{ATP}] /[\mathrm{ADP}] \times[\mathrm{Pi}]) ; \mathrm{TC} P C \mathrm{r}$, time constant of phosphocreatine resynthesis rate after exercise. 
nucleotide change- $\mathrm{a} G \rightarrow \mathrm{A}$ heteroplasmic transition at position 13042 of the ND5 subunit gene. This mutation induces the A236T amino acid change at an invariant position, as shown by the alignment of multiple ND5 sequences (fig 3). The A236T amino acid change is from a non-polar, hydrophobic to a polar, hydrophilic residue, the latter having also a slightly larger steric volume.

The complete sequence of 1155 mtDNAs is available from previous reports and public databases, including 412 belonging to haplogroup $\mathrm{H}$ and seven to $\mathrm{H} 13 .^{21}$ The $13042 \mathrm{G} \rightarrow \mathrm{A}$ transition was not observed in any of these sequences and is not reported in the Mitomap database (http://www.mitomap.org/).

The MseI restriction survey of mtDNA from multiple tissues (blood, urinary epithelium, and skeletal muscle) from the two living affected individuals and eight maternal relatives showed the heteroplasmic $13042 \mathrm{G} \rightarrow \mathrm{A} / \mathrm{ND} 5$ mutation present at a variable load in all but two of the subjects (V-5 and V-13) (fig 4). The mutation was invariably more abundant in the urinary epithelium and skeletal muscle, while it was barely present in the blood, as usually seen in severe pathogenic mtDNA mutations. Moreover, the mutant mtDNA was passed at very low loads, or not at all, in at least three mother-offspring segregations (IV-4>V-5, IV-4>V-6, and IV$14>\mathrm{V}-13)$, but did increase in a further mother-offspring segregation (IV-14 $>$ V-12).

Proband's in vivo investigation of occipital lobes by ${ }^{31} \mathrm{P}$ MRS showed abnormal indices of mitochondrial function (table 2). Calf muscle [PCr] and [Pi] at rest were within the normal range. On the other hand, the time constant of $\mathrm{PCr}$ post-exercise resynthesis - which reflects mitochondrial ATP production rate-was markedly increased, indicating impaired oxidative phosphorylation (table 2).

\section{DISCUSSION}

The $13042 \mathrm{G} \rightarrow \mathrm{A} / \mathrm{ND} 5$ mtDNA mutation found in an Italian family with a prevalent phenotype of LHON-like visual loss, but also with evidence of retinopathy and cataract, fulfils the following common criteria for being pathogenic. First, it is the only non-synonymous mutation distinguishing the family's mtDNA and introduces the A236T amino acid change adjacent to the other pathogenic M237L amino acid change, ${ }^{5}$ both being invariant positions in a very highly conserved domain of the ND5 subunit gene of complex I. Second, the $13042 \mathrm{G} \rightarrow \mathrm{A} / \mathrm{ND} 5$ mutation was absent in a very large number of control mtDNAs, including many belonging to the same haplogroup. Third, the $13042 \mathrm{G} \rightarrow \mathrm{A}$ mutation was heteroplasmic, with the highest proportion of mutant mtDNA in the proband and her affected brother and strikingly lower mutational loads in blood compared with urinary epithelium (and skeletal muscle). This suggests a strong selection against the mutant mtDNA in a fast turnover tissue, similar to other severe mtDNA pathogenic mutations..$^{22}$ Fourth, the functional relevance of the mutation is supported by ${ }^{31} \mathrm{P}$ MRS investigations which demonstrated, as for other mtDNA pathogenic mutations, a severe defect of oxidative metabolism in both brain and skeletal muscle of the proband. ${ }^{23}$ Finally, a single patient with a different phenotype (MERRF/ MELAS) has recently been reported to harbour the same mutation. ${ }^{15}$

Thus the detection of the $13042 \mathrm{G} \rightarrow \mathrm{A}$ mutation in an Italian family not only conclusively establishes its pathogenic role, but underscores its variable clinical expression. The two living affected individuals suffered an LHON-like optic neuropathy with some atypical features. ${ }^{24}$ The onset of visual loss was unusually late, and both cases experienced a good recovery of visual acuity, apparently after surgery. Both histopathological reports on the arachnoid specimen mentioned inflammatory features, which are also not typical in classic LHON. Moreover, besides the optic neuropathy the two living affected individuals-as well as some of the unaffected carriers-also had evidence of further ocular involvement, with retinopathy characterised by yellowish dots distributed both in the peripheral and central retina, and cataract. The proband and her brother had the most severe ocular involvement, possibly related to the higher load of mutant mtDNA. While the retinopathy here described has rarely been seen in association with classical LHON patients, ${ }^{25}$ the early onset cataract seems not to have been reported previously in LHON, but has occasionally been observed (Barboni P, Carelli V, unpublished observation). However, both retinopathy and cataract may be relatively common in mitochondrial encephalomyopathies. ${ }^{25} 26$

Visual loss in the proband was accompanied by migraine attacks, with some resemblance to MELAS. Easy fatigability and increased lactic acid in the serum were consistently found after effort. The proband's mother most probably had late MELAS complicating her early optic neuropathy and she had had three miscarriages. The three early deathsparticularly those reported as "meningitis" - are difficult to interpret, but a Leigh-like encephalopathy could have been overlooked.

In conclusion, we report the second case of a novel mutation in the ND5 gene associated with a prevalent ocular clinical expression, but possibly also with MELAS and Leigh clinical phenotypes, as previously seen with companion mutations in the ND5, ND6, and NDl genes. We suggest the inclusion of all these mutations in the standard screening protocols for LHON patients when a search fails to find the classical ones, and atypical clinical manifestation are recognised along the maternal line.

\section{ACKNOWLEDGEMENTS}

We thank all the individuals from the pedigree for their collaboration. We acknowledge the support of Fondazione Gino Galletti (to VC), Progetto CNR-MIUR Genomica Funzionale-Legge 449/97 (to $\mathrm{AT}$ ), Fondo Investimenti Ricerca di Base 2001 (to AT), and the partial support of Telethon-Italy Fondazione Onlus (grant No GGP02323 to VC).

\section{Authors' affiliations \\ M L Valentino, F Fortuna, P Montagna, A Baruzzi, V Carelli,} Dipartimento di Scienze Neurologiche, Università di Bologna, Bologna, Italy

P Barboni, Centro Oftalmologia Salus, Bologna, Italy

C Rengo, A Achilli, A Torroni, Dipartimento di Genetica e

Microbiologia, Università di Pavia, Pavia, Italy

R Lodi, C Tonon, B Barbiroli, Dipartimento di Medicina Clinica e

Biotecnologia Applicata "D Campanacci", Università di Bologna, Bologna, Italy

Conflicts of interest: none declared

Correspondence to: Dr Valerio Carelli, Dipartimento di Scienze Neurologiche, Università di Bologna, Via Ugo Foscolo 7, 40123, Bologna, Italy; carelli@neuro.unibo.it

Received 29 July 2005

Revised version received 12 December 2005

Accepted for publication 13 December 2005

\section{REFERENCES}

1 Santorelli FM, Tanji K, Kulikova R, Shanske S, Vilarinho L, Hays AP, DiMauro $S$. Identification of a novel mutation in the mtDNA ND5 gene associated with MELAS. Biochem Biophys Res Commun 1997;238:326-8.

2 Pulkes T, Eunson L, Patterson V, Siddiqui A, Wood NW, Nelson IP, MorganHughes JA, Hanna MG. The mitochondrial DNA G13513A transition in ND5 is associated with a LHON/MELAS overlap syndrome and may be a frequent cause of MELAS. Ann Neurol 1999;46:916-19.

3 Penisson-Besnier I, Reynier P, Asfar P, Douay O, Sortais A, Dubas F, Emile J Malthiery Y. Recurrent brain hematomas in MELAS associated with an ND5 gene mitochondrial mutation. Neurology 2000;55:317-18. 
4 Corona P, Antozzi C, Carrara F, D'Incerti L, Lamantea E, Tiranti V, Zeviani M. A novel mtDNA mutation in the ND5 subunit of complex I in two MELAS patients. Ann Neurol 2001;49:106-10.

5 Liolitsa D, Rahman S, Benton S, Carr U, Hanna MG. Is the mitochondria complex I ND5 gene a hot-spot for MELAS causing mutations? Ann Neurol 2003;53:128-32

6 Taylor RW, Morris AA, Hutchinson M, Turnbull DM. Leigh disease associated with a novel mitochondrial DNA ND5 mutation. Eur J Hum Genet 2002;10:141-4.

7 Chol M, Lebon S, Benit P, Chretien D, de Lonlay P, Goldenberg A, Odent S, Hertz-Pannier L, Vincent-Delorme C, Cormier-Daire V, Rustin P, Rotig A, Munnich A. The mitochondrial DNA G13513A MELAS mutation in the NADH dehydrogenase 5 gene is a frequent cause of Leigh-like syndrome with isolated complex I deficiency. J Med Genet 2003;40:188-91.

8 Petruzzella V, Di Giacinto G, Scacco S, Piemonte F, Torraco A, Carrozzo R, Vergari R, Dionisi-Vici C, Longo D, Tessa A, Papa S, Bertini E. Atypical Leigh syndrome associated with the D393N mutation in the mitochondrial ND5 subunit. Neurology 2003;61:1017-18.

9 Kirby DM, Boneh A, Chow CW, Ohtake A, Ryan MT, Thyagarajan D, Thorburn DR. Low mutant load of mitochondrial DNA G13513A mutation can cause Leigh's disease. Ann Neurol 2003;54:473-8

10 Sudo A, Honzawa S, Nonaka I, Goto Y. Leigh syndrome caused by mitochondrial DNA G13513A mutation: frequency and clinical features in Japan. J Hum Genet 2004;49:92-6.

11 Crimi M, Galbiati S, Moroni I, Bordoni A, Perini MP, Lamantea E, Sciacco M, Zeviani M, Biunno I, Moggio M, Scarlato G, Comi GP. A missense mutation in the mitochondrial ND5 gene associated with a Leigh-MELAS overlap syndrome. Neurology 2003;60:1857-61.

12 Ravn K, Wibrand F, Hansen FJ, Horn N, Rosenberg T, Schwartz M. An mtDNA mutation, 14453G $\rightarrow A$, in the NADH dehydrogenase subunit 6 associated with severe MELAS syndrome. Eur J Hum Genet 2001;9:805-9.

13 Kirby DM, McFarland R, Ohtake A, Dunning C, Ryan MT, Wilson C, Ketteridge D, Turnbull DM, Thorburn DR, Taylor RW. Mutations of the mitochondrial NDI gene as a cause of MELAS. J Med Genet 2004;41:784-9.

14 Blakely EL, de Silva R, King A, Schwarzer V, Harrower T, Dawidek G, Turnbull DM, Taylor RW. LHON/MELAS overlap syndrome associated with a mitochondrial MTND1 gene mutation. Eur J Hum Genet 2005; 13:623-7.

15 Naini AB, Lu J, Kaufmann P, Bernstein RA, Mancuso M, Bonilla E, Hirano M, DiMauro S. Novel mitochondrial DNA ND5 mutation in a patient with clinical features of MELAS and MERRF. Arch Neurol 2005;62:473-6.
16 Torroni A Rengo C Guida V Cruciani F, Sellitto D Coppa A Calderon FL, Simionati B, Valle G, Richards M, Macaulay V, Scozzari R. Do the four clades of the mtDNA haplogroup L2 evolve at different rates? Am J Hum Genet 2001;69:1348-56.

17 Valentino ML, Avoni P, Barboni P, Pallotti F, Rengo C, Torroni A, Bellan M, Baruzzi A, Carelli V. Mitochondrial DNA nucleotide changes C14482G and C14482A in the ND6 gene are pathogenic for Leber's hereditary optic neuropathy. Ann Neurol 2002;51:774-8.

18 EEC Concerted Research Project. Quality Assessment in in vivo NMR spectroscopy. Results of a concerted Research Project of the European Economic Community (6 papers). Magnetic Reson Imaging 1995; 13:1 15-76.

19 Lodi R, Montagna P, Cortelli P, lotti S, Cevoli S, Carelli V, Barbiroli B. "Secondary" 4216/ND1 and 13708/ND5 Leber's hereditary optic neuropathy mtDNA mutations do not further impair mitochondrial oxidative metabolism deficit due to 11778 /ND4 mtDNA mutation. An in vivo brain and skeletal muscle phosphorus MR spectroscopy study. Brain 2000;123:1896-902

20 Bottomly PA, Hardy CJ. Rapid, reliable in vivo assay of human phosphate metabolites by nuclear magnetic resonance. Clin Chem 1989:59:392-5.

21 Achilli A, Rengo C, Magri C, Battaglia V, Olivieri A, Scozzari R, Cruciani F, Zeviani M, Briem E, Carelli V, Moral P, Dugoujon JM, Roostalu U, Loogvali EL, Kivisild T, Bandelt HJ, Richards M, Villems R, Santachiara-Benerecetti AS, Semino O, Torroni A. The molecular dissection of mtDNA haplogroup $\mathrm{H}$ confirms that the Franco-Cantabrian glacial refuge was a major source for the European gene pool. Am J Hum Genet 2004;75:910-18.

22 Rahman S, Poulton J, Marchington D, Suomalainen A. Decrease of 3243 $A \rightarrow G$ mtDNA mutation from blood in MELAS syndrome: a longitudinal study. Am J Hum Genet 2001;68:238-40.

23 Valentino ML, Barboni P, Ghelli A, Bucchi L, Rengo C, Achilli A, Torroni A, Lugaresi A, Lodi R, Barbiroli B, Dotti M, Federico A, Baruzzi A, Carelli V. The ND1 gene of complex I is a mutational hot spot for Leber's hereditary optic neuropathy. Ann Neurol 2004:56:631-41.

24 Carelli V, Ross-Cisneros FN, Sadun AA. Mitochondrial dysfunction as a cause of optic neuropathies. Prog Retin Eye Res 2004;23:53-89.

25 Isashiki Y, Nakagawa M, Ohba N, Kamimura K, Sakoda Y, Higuchi I, Izumo S, Osame M. Retinal manifestations in mitochondrial diseases associated with mitochondrial DNA mutation. Acta Ophthalmol Scand 1998;76:6-13

26 Rummelt V, Folberg R, lonasescu V, Yi H, Moore KC. Ocular pathology of MELAS syndrome with mitochondrial DNA nucleotide 3243 point mutation. Ophthalmology 1993;100:1757-66. 